\title{
EL PREMIO DE LA PLATA: LA PRIMA DE RIESGO DEL SIGLO XVII
}

\author{
The Premium of Silver: The Risk Premium \\ of the XVII century
}

JAIME HERNÁN-PÉREZ AGUILERA*

Fecha de recepción: 20 de octubre de 2020

Fecha de aceptación: 8 de marzo de 2021

\section{Introducción}

En el verano de 2012, en plena crisis de deuda soberana en la UE, el entonces gobernador del BCE, Mario Draghi, lanzó un mensaje para calmar a los mercados financieros: "The ECB is ready to do whatever it takes to preserve the euro." En el fondo estaba transmitiendo que si era necesario crear dinero de la nada o expandir artificialmente la masa monetaria, se haría, o lo que es lo mismo, si había que manipular el dinero, se haría. Desde el origen de los primeros imperios, y con la creación de los estados modernos, la manipulación del dinero en beneficio de la acción política ha sido un recurso que los políticos no han dudado en utilizar. Los Emperadores Romanos, Enrique VIII de Inglaterra o Felipe IV de España, muchos gobernantes manipularon el dinero, esperando con ello solucionar sus problemas financieros. Sin embargo, lo único que consiguieron fue inflación, destrucción de la actividad económica y un agravamiento de la crisis que pretendían solucionar.

\footnotetext{
* Doctor en Economía por la Universidad Rey Juan Carlos. Premio Extraordinario de Doctorado. Licenciado en Económicas por la Universidad Complutense. Licenciado en Historia por la UNED. Diploma en Estudios Avanzados de Historia Moderna por la UNED. Email: sercojaime@gmail.com.
} 
La intervención del gobierno de la monarquía sobre la moneda con una finalidad fiscal fue un arbitrio profusamente utilizado en Castilla durante la época de gobierno de la Casa de Austria, especialmente en los reinados de Felipe III y Felipe IV. En estos años confluyen el auge del absolutismo político con las cada vez más acuciantes necesidades de la Monarquía Hispánica, que se desangraba desde el punto de vista financiero como consecuencia del monumental esfuerzo que suponía el mantenimiento de los frentes bélicos en el norte de Europa. Para financiar la política imperial, la Corona recurrió a todo tipo de arbitrios que le permitiesen incrementar sus ingresos, y en ese contexto se incardinan las manipulaciones monetarias del siglo XVII, que han sido, quizás, uno de los rasgos que mejor definen la llamada Decadencia o crisis castellana del siglo XVII.

El continuo intervencionismo del gobierno sobre el dinero destruyó el sistema monetario imposibilitando la fijación de precios, el cálculo económico y el libre ejercicio de la función empresarial. Los agricultores y artesanos, comerciantes e incluso los hombres de negocios vieron cómo las señales que emplea el mercado para decidir sobre dónde y cuándo invertir fueron manipuladas al servicio de una política del gobierno. Las consecuencias de la manipulación del dinero, primero en forma de una elevada inflación, y después con la aparición del premio de la plata, terminaron por agravar aún más la crisis de la economía del siglo XVII.

\section{Consideraciones en torno a la cuestión del origen e importancia del dinero}

En su estricta definición, el dinero es un medio de intercambio comúnmente aceptado por todos los individuos. El dinero facilita e incrementa los intercambios comerciales, y participa activamente en la creación de otras instituciones que impulsan el desarrollo y la cooperación social. Si no existiera el dinero, el número de intercambios se reduciría destruyendo todo el tejido económico y social.

En torno al origen del dinero existen tantas teorías como escuelas de pensamiento económico. Tradicionalmente la historiografía sitúa el origen del dinero en la antigua Grecia, en concreto en Lidia. 
El gran historiador Herodoto menciona a Creso, el cual envió un regalo de dos estateras de oro a cada uno de los habitantes de la ciudad de Delfos. El comercio a larga distancia jugó un papel significativo en el uso de los metales preciosos como dinero, porque debió de ser crucial para los mercaderes vender sus bienes en todas las regiones del Mediterráneo. Para Aristóteles, el dinero se inventó como un medio para comparar el valor de las cosas y facilitar la actividad comercial, es decir, con un uso natural, pero servirse del dinero para obtener ganancias con el mismo, como con el trabajo asalariado y sobre todo con el préstamo con interés, era un uso no natural. En torno a esta consideración de Aristóteles se establecería un profundo debate durante toda la Edad Media, especialmente por los escolásticos.

Las ideas de los escolásticos se basaban principalmente en Aristóteles, y confluían a menudo con ideas políticas, especialmente en el caso de la función del gobernante en relación con el dinero. Para los escolásticos, el dinero tenía dos funciones distintas, era una medida de valor artificial autorizada por el Estado, con la cual se podían medir todas las cosas pero al aparecer las monedas de metales preciosos, empezó a ser considerado como un bien con un valor que podía subir y bajar, como cualquier otro bien, de hecho, Tomás de Aquino comparaba las riquezas naturales que satisfacen las necesidades humanas con la riqueza artificial producida por el hombre, donde el dinero es una de ellas que sirve como medio de intercambio y medida.

El desarrollo comercial europeo de los siglos XII a XIV y sobre todo el descubrimiento de América y los nuevos Estados Nacionales favorecieron como nunca antes el uso del dinero como medio de intercambio, pero también como medio de financiación, porque los gobernantes descubrieron nuevas formas de financiación no solo con impuestos, sino con deuda, además de la ya tradicional del recurso al envilecimiento de la moneda. En este sentido, la figura de Juan de Mariana es esencial para identificar los problemas derivados de manipular el dinero. Juan de Mariana distingue entre valor intrínseco, valor natural de mercado de la moneda y valor extrínseco, el valor que, forzosamente, le otorga el Rey. El conflicto surge cuando estos dos valores se divorcian fruto de la inflación. La gran contribución del padre Mariana será la de ser el 
primero en establecer una relación clara y nítida, en un estudio sistemático, de cómo el incremento de la masa monetaria, analizado desde el punto de vista del envilecimiento de la moneda, conduce inevitablemente a una subida de los precios.

Frente a estas interpretaciones, la Escuela Austriaca de Economía precisa que el dinero no surge por arte de magia, sino como consecuencia de decisiones que han sido tomadas racionalmente por quienes están directamente interesados en hacer uso del mismo en los intercambios de bienes y servicios, de manera espontánea y a través de un largo proceso de selección, sin que el Estado o cualquier autoridad legal intervenga en ello, salvo para preservarlo y mantenerlo. El dinero se materializó en metales preciosos, en oro y plata, que eran posesiones valiosas por ellas mismas, fácilmente transportables e intercambiables por otros bienes. El hecho de que los metales no estuvieran sometidos a deterioro ni a fluctuaciones anuales en el suministro aumentó sus utilidades. El oro y la plata se convirtieron en mercancías de uso común porque mantenían unas características que los hace únicos y por lo tanto los convierte en medio de pago aceptado. Por un lado son escasos, lo que permite aplicar la ley de utilidad marginal decreciente y convertirlos así en materiales que acumulan gran valor. Son homogéneos, lo que hace más sencillo comprobar la ley, y todas sus partes son equiparables, y además inmutables. Así pues, el uso y costumbre había escogido diversos bienes que los individuos demandaban activamente y que por lo tanto consideraban un depósito de valor, el oro y la plata.

Junto a la aparición del dinero, los gobernantes descubrieron que era posible obtener beneficios de su acuñación. Para que la acuñación de moneda produzca beneficios a los estados debía estar regulado por la autoridad legal, ya que era un derecho exclusivo del soberano o gobernante, una regalía que permitía modificar el peso, la ley o el valor de las monedas y que fue utilizada en su propio beneficio por el poder político, casi siempre por motivos fiscales.

En torno a las manipulaciones monetarias, la Escuela Austriaca estudia con profundidad no solo las consecuencias legales que se derivan de las mismas, sino la alteración que produce en el mecanismo del cálculo económico, en la formación de los precios y en la función empresarial de los individuos. Para Mises, el dinero es ante todo un medio común de cambio que el mercado ha seleccionado 
como tal y no una creación de la ley, y es mediante este resquicio por donde penetran todas las doctrinas inflacionistas. Para que el dinero tenga valor de uso es necesario que tenga antes valor de cambio, pero y es aquí donde introduce un matiz principal, se precisa un valor de cambio basado en alguna otra cosa distinta a su función monetaria para que un bien pueda ser considerado dinero, de ahí el papel que ha jugado el oro y los metales preciosos en toda la historia de la humanidad, y la posterior aparición de los sustitutos monetarios, esto es, los billetes de banco o los cheques, que funcionan como el dinero, pero no son dinero. En definitiva, la manipulación en el valor del dinero trae como consecuencia la inflación, que no es fruto de la acción humana, sino más bien de la acción de los gobiernos.

Otro análisis certero es el que ofrece Rothbard cuando señala los beneficios que se darían en una economía si la moneda es independiente del gobierno, mientras considera lo perniciosas que pueden llegar a ser las intervenciones en materia monetaria, que derivan habitualmente en el monopolio compulsivo de la emisión, en leyes de curso forzoso o en la suspensión de pagos en metálico por los bancos.

El recurso a las manipulaciones monetarias fueron constantes por parte de los gobiernos que conformaban las monarquías absolutas europeas en los siglos XVI y XVII, pero antes es preciso analizar cómo funcionaba el mercado monetario.

\section{El mercado monetario en los siglos XVI y XVII}

Bien en pleno siglo XXI, o bien en los siglos XVI y XVII, existen tres factores que influyen directamente en la evolución del numerario de un país. En primer lugar la actividad económica, ya que a media que esta crece o decrece se otorga un mayor o menor valor a la moneda. En segundo lugar la propia sociedad, los individuos que la conforman, ya que realizan una estimación subjetiva y/o de valor que considera para cada moneda ${ }^{1}$. Finalmente y en tercer

\footnotetext{
${ }^{1}$ Efectivamente como afirma L. von Mises, "Las apreciaciones subjetivas de los individuos son la base de la valoración económica del dinero como de la de los demás bienes". L. von Mises (2012): La acción humana, Cap. VII, p. 71, Unión Editorial, Madrid.
} 
lugar las razones políticas, que pueden alterar las dos anteriores, y que son el origen de las profundas alteraciones monetarias que sufriría el mercado monetario en los siglos XVI y XVII en España.

En cuanto a los valores del numerario, cada moneda tiene dos valores de referencia, el intrínseco derivado del valor de la cantidad de metal utilizado en su acuñación ${ }^{2}$, es decir, del valor de su contenido en oro, plata o cobre, y el valor extrínseco o nominal, establecido por la autoridad monetaria competente. Era complejo hacer que ambos coincidieran, pero además hay un tercer factor que complicaba este delicado equilibrio y es el valor que el público percibe en función a sus preferencias de uso. Para complicar más todo, en el siglo XVII el sistema monetario de Castilla era bimetálico, basado en el oro y en la plata como metales de referencia, y una moneda, la moneda de vellón de cobre, con bajo contenido en plata o ligada, que cumplía en el sistema la función de ser moneda fraccionaria, y por lo tanto la moneda de uso común por la población para el comercio, lo que podría asimilarse con un sistema trimetálico en la práctica.

Los Reyes Católicos definieron en la Pragmática de Medina del Campo $^{3}$, decretada el 13 de junio de 1497, las normas referentes al peso, ley y valor en cada unidad de cuenta que debían respetar cada una de las piezas circulantes, tratando de ajustar los valores extrínseco e intrínseco de la moneda a la situación del mercado, y sobre todo de la percepción subjetiva de los individuos. Como moneda de oro principal quedó establecida el ducado castellano, pieza que debía ser acuñada a razón de $651 / 3$ piezas por marco, por lo que su peso quedaba establecido en 3,49 gramos, con una ley de $233 / 4$ quilates. Su equivalencia en unidad de cuenta quedaba fijada en 375 maravedís ${ }^{4}$. En cuanto a la moneda de plata, la Pragmática de Medina del Campo ordenaba que se continuaran

2 A este respecto señala Mises: “El valor de la moneda lo ha fijado siempre, no la imagen e inscripción que lleva ni la proclamación de las autoridades, sino su contenido metálico. No toda clase de moneda se ha aceptado a primera vista, sino tan sólo aquellas clases que poseían una buena reputación por peso y pureza". L. von Mises, ob. cit., p. 38 .

${ }^{3}$ Nueva Recopilación, Libro V, Título XXI, Ley IX. Biblioteca Digital Castilla y León, www.bibliotecadigital.jcyl.es

${ }^{4}$ Nueva Recopilación, Libro V, Título XXI, Ley I. 
labrando reales, cuyo peso debía ser de 3,43 gramos, lo que implicaba 67 piezas por marco y su ley 11 dineros y 4 granos. El valor en unidad de cuenta fue establecido en 34 maravedís.

Así pues, la Monarquía Hispánica, en los siglos XVI y XVII mantenía, al igual que otras naciones europeas, un sistema monetario formado por monedas de oro y plata ${ }^{5}$, aunque posteriormente se añadió la moneda de cobre con aleación o liga de plata, también conocida como moneda de vellón, es decir, era un sistema bimetálico o trimetálico si se tiene en cuenta la moneda de cobre.

El proceso de emisión de la moneda comenzaba en las Casas de Moneda, también conocidas como Cecas. La gestión de las cecas se realizaba mediante la administración directa por parte de las autoridades públicas con el nombramiento de una serie de funcionarios, que eran pagados con los beneficios obtenidos de los derechos de braceaje y señoreaje, o bien mediante el arrendamiento a un mercader o empresario a cambio de un canon fijo. Por lo tanto, aunque en principio el proceso de emisión de moneda era libre, en realidad estaba controlado por la autoridad, en nuestro caso la Corona.

La producción de moneda efectiva nacía de un ejercicio de libertad, del encuentro de dos voluntades, por un lado los particulares que vendían a la ceca el metal precioso para obtener las monedas pagando una cantidad por la gestión (el braceaje y el señoreaje), y por el otro la ceca, que procedía a la amonedación del metal en base a los precios y valores legalmente establecidos. Un aspecto destacable es el número de cecas abiertas, y es que en Castilla pero en general en todos los estados europeos se asiste a un progresivo cierre de las mismas, conforme el poder estatal se refuerza y su intervención sobre la actividad económica es mayor. En el caso de Castilla, por ejemplo, el número de cecas con licencia para fabricar moneda eran seis, Burgos, La Coruña, Cuenca, Toledo, Sevilla y Segovia, cuya ceca sería fundamental en las emisiones de moneda de vellón.

${ }^{5}$ Los Reyes Católicos fijaron el sistema monetario con su ley y equivalencia en la Pragmática de Medina del Campo, publicada el 13 de junio de 1497 y que permaneció prácticamente inalterada durante los siglos XVI y XVII. Nueva Recopilación, Libro V, Título XXI, Ley IX. 
Dentro del proceso de acuñación hay que tener en cuenta los costes de fabricación de las monedas. Por un lado el del propio metal empleado, así por ejemplo, durante las grandes emisiones de monedas de vellón el precio internacional del cobre subió de manera espectacular. Por otro las cecas debían pagar a sus operarios, para ello recaudaban por sus servicios el braceaje. A ello había que sumar el impuesto de señoreaje, el ingreso que obtenía el Rey por esta regalía, y finalmente habría que añadir el coste del transporte, pues exigía medios y seguridad para desplazar las monedas acuñadas ${ }^{6}$.

A todo este complejo sistema monetario se añadía otro elemento más, la moneda de cuenta. El sistema monetario utilizaba unidades abstractas para medir el valor, esto es, la moneda de cuenta, con las cuales se miden los valores y las proporciones numéricas a las que están ligadas las monedas acuñadas. Los precios, los salarios y los contratos venían estipulados en moneda de cuenta, una especie de dinero imaginario que servía de medida para la moneda en circulación. Cada moneda de cuenta equivalía a una cantidad de metal previamente fijada. La unidad de cuenta castellana era el maravedí, así por ejemplo, el ducado castellano, la moneda de oro que se acuñaba, tenía un peso de 3,49 gramos de oro y equivalía a 375 maravedíes. En general cuando se fijaba un precio y en la compraventa no se especificaba nada, se aludía a valores que podían ser liquidados con moneda valorada al curso legal, pero en otros casos el valor se indicaba en moneda de cuenta pero prefijado a un valor determinado con la moneda legal, debido a que el valor intrínseco no estaba ajustado por los efectos de las alteraciones monetarias, así como por una tendencia constante a perder valor por parte de la moneda de cuenta. La moneda de cuenta mantenía una constante tendencia a la devaluación, lo que añadía un componente más a la inestabilidad del mercado monetario.

\footnotetext{
${ }^{6}$ A medida que las alteraciones monetarias y el premio de la plata incrementaron el nivel de precios y las cantidades de dinero necesarias para adquirir bienes, los costes de transporte de moneda fueron aumentando. Carlos Álvarez Nogal (2000): El transporte de moneda en la España del siglo XVII: mecanismos y costes. Dpto. Historia Económica Universidad Carlos III.
} 
Por otra parte, para la actividad comercial y los hombres de negocios, la prueba que medía la salud del mercado monetario era la relación de cambio de las monedas preciosas con las monedas fraccionarias, es decir, las de uso cotidiano. La relación que había entre ambas es conocida como cambio interno o vertical, es decir, el valor de intercambio entre las monedas grandes o gruesas y las pequeñas. Este valor, previamente ajustado al estar medido en monedas de cuenta, sufría constantes cambios y variaciones por diversas razones, como era un crecimiento de la población y de la actividad económica, que aumentaba la velocidad de circulación de las monedas y por lo tanto su relación de cambio. La introducción de monedas pequeñas de vellón, las que tenían alteraciones en el peso y sobre todo la introducción masiva de moneda falsa, alteraban también la relación de cambio, haciendo desaparecer las monedas gruesas de metal precioso, es decir, el mercado aplicaba la Ley de Gresham y ajustaba los valores.

La Monarquía Hispánica hubiera podido garantizar la estabilidad de las tasas de cambio limitando las acuñaciones de monedas fraccionarias y garantizando la plena convertibilidad con las monedas gruesas, pero no fue así. La inestabilidad de los valores de cambio fue constante. A medida que las monedas fraccionarias envilecían su paridad con las monedas preciosas y se incrementaba su equivalencia, se devaluaba su valor, y a pesar de que esta devaluación podía suponer una oportunidad para poder exportar más bienes y por lo tanto, obtener más moneda, no fue así, ya que la inflación generalizada por el aumento de los costes de producción, las masivas acuñaciones de moneda de vellón y las alteraciones monetarias, contribuyeron a desajustar los cambios, los precios, el cálculo económico y en general toda la economía castellana.

En resumen, la acuñación de moneda era un derecho exclusivo del soberano, una regalía que permitía modificar el peso, la ley o el valor de las monedas y que fue utilizada casi siempre con motivos fiscales. Sobre esta fiscalidad se apoyaría el ejercicio de alterar el valor de la moneda, a través de la reducción de la ley o mediante el resello. En ambos casos, lo que buscaba el poder político era obtener un beneficio económico manipulando el valor del dinero. La conjunción de todos los costes de acuñación, de los valores extrínsecos e intrínsecos de cada moneda, de la estimación que cada una 
de ellas tenía en el mercado, unidas a la manipulación del dinero, provocaron una serie de movimientos económicos a consecuencia de la política monetaria ejercida por la monarquía hispánica. Uno de ellos, que generó enormes quebraderos de cabeza a los responsables políticos, sería el llamado premio de la plata.

\section{La política monetaria de la Monarquía Hispánica en los siglos XVI y XVII}

En el siglo XVII las tesis mercantilistas asociaban el concepto de riqueza de un país con la cantidad de oro y plata que poseía. Se trataba de conservar el stock monetario y de ampliarlo todo lo que fuera posible, evitando la salida de monedas con la prohibición o los estrictos controles sobre las importaciones, y favoreciendo las exportaciones. Por otra parte, en el subconsciente de los habitantes estaba la preferencia por la sobreabundancia de monedas, ya que en línea con el pensamiento económico mercantilista de la época, a más cantidad de moneda, mayor riqueza se poseía. Esto no era otra cosa que introducir el valor subjetivo de los individuos sobre la demanda de dinero. Como bien señala Mises:

“Todos los agentes económicos se ven precisados a tener una cantidad del medio común de cambio suficiente para cubrir sus probables necesidades personales y de negocios. La cantidad precisa dependerá de circunstancias individuales. Está influida tanto por las costumbres y hábitos del individuo como por la organización del conjunto del aparato social de producción y cambio". ${ }^{7}$

Los principios mercantilistas de la competencia entre Estados, subordinando la economía a un feroz proteccionismo y a una extrema competitividad por el acceso de los productos a los mercados, encontraron su reflejo en las monedas. Esta conflictividad comercial se traslada a la vertiente monetaria utilizando varias estrategias, como son las tasas de cambios, la propia especulación,

\footnotetext{
7 L. von Mises, ob. cit., Cap. VIII, p. 106.
} 
y las alteraciones monetarias, muy comunes en Europa durante el siglo XVII.

La política monetaria llevada a cabo por la Monarquía Hispánica a lo largo de los siglos XVI y XVII sólo tuvo un fin exclusivamente fiscal. Tanto en el caso de las masivas acuñaciones de moneda de vellón, como en las alteraciones de esta moneda a través de la rebaja de su ley o modificando su valor facial, en todos los casos el objetivo de las medidas no era otro que obtener recursos adicionales para financiar el gigantesco déficit público derivado de una política imperial cuyos costes eran inasumibles. En ningún caso se planteó la reactivación económica o el control de los precios, todo quedó supeditado a ofrecer más recursos para la Hacienda Real. El resultado final sería una moneda inestable, en la que ningún agente tenía confianza.

Una circunstancia que tuvo un profundo, intenso y duradero efecto sobre la política monetaria de Castilla fue el descubrimiento de América. Al disponer la monarquía de enormes cantidades de plata, que entonces era un bien de ilimitada liquidez en el mercado internacional, y por lo tanto con una demanda muy elevada, se generalizó la acuñación de monedas de plata de gran tamaño, estableciendo con ello una moneda fuerte para atraer crédito internacional $^{8}$ y con ello financiación para los crecientes gastos del nuevo estado. Esta moneda de plata producirá una sensible modificación de la relación entre oro y plata, ya que el precio de ambos estaba sujeto al lógico juego del mercado entre oferta y demanda, de ahí que las alteraciones del coeficiente bimetálico fueran frecuentes y no ajustadas por la autoridad monetaria, siempre por mantener una paridad alta de la moneda de plata'.

Con el inicio del siglo XVII, el delicado equilibrio en el que se sustentaban los sistemas monetarios europeos fue puesto a prueba por las crecientes emisiones de moneda fraccionaria debido al

8 Carlos Álvarez Nogal (2000): El dilema monetario de la monarquía española en el siglo XVII. ¿Pequeñas monedas de plata o crédito internacional?, Dpto. Historia Económica Universidad Carlos III.

9 Sobre las necesidades de mantener una moneda de plata fuerte para garantizarse el acceso al crédito internacional destacamos los trabajos de Cecilia Font de Villanueva (2005): "Política monetaria y política fiscal en Castilla en el siglo XVII: un siglo de inestabilidades." Revista de Historia Económica. 
aumento de las necesidades de financiación de los estados, dando lugar a un proceso de constante aumento de los precios. La moneda pequeña o fraccionaria era emitida casi exclusivamente por cuenta del estado a través de su acuñación en las cecas, obteniendo un beneficio representado por la diferencia entre el valor nominal y el valor intrínseco, beneficio que iba a parar a las arcas reales y que se destinaba básicamente a financiar la política exterior de la monarquía, el gasto de la Casa Real y de la creciente burocracia. Por otra parte, las piezas fraccionarias eran el medio usual de pago de los salarios y del comercio al por menor, eran la moneda de uso cotidiano, mientras que la moneda de oro y de plata se utilizaba por los hombres de negocios y la Real Hacienda. Este hecho hacía más gravoso para la población cualquier cambio de valoración o de emisión de la moneda de cobre.

La acuñación de la moneda baja permitía a los soberanos obtener ingentes ganancias. El hecho de que su acuñación fuera casi un monopolio estatal y de que la elasticidad de su demanda fuera pequeña, convirtió a estas monedas en una cómoda fuente de ingresos; el pueblo las necesitaba para su gasto diario y no podía sustituirlas con facilidad. El problema de utilizar moneda de vellón era determinar bien su cantidad en circulación, pues cualquier exceso de cantidad aumentaba los precios. Las Cortes de Castilla y la pragmática de Medina del Campo fijaron en el régimen de acuñación de piezas una total libertad en el caso de las monedas de oro y plata, mientras que las acuñaciones de vellón quedaban estrictamente limitadas a diez millones de maravedíes, cantidad suficiente para las necesidades monetarias del comercio, por ello, las Cortes reclamaban insistentemente que las emisiones de vellón fueran controladas, pues temían las amargas consecuencias que producían las expansiones de moneda incontroladas.

Los Reyes Católicos realizaron una política económica que buscaba, entre otros objetivos, la estabilidad monetaria. A la muerte de Enrique IV no existía un numerario capaz de regular de forma adecuada el comercio interior del reino y en el exterior se sufría una desigualdad existente respecto de la moneda europea, más evolucionada y adaptada que la castellana. La reforma monetaria que adoptaron en línea con los principios mercantilistas quería evitar la salida de moneda, acabar con el fraude en las cecas y controlar la 
calidad de las emisiones. El enorme prestigio de la reforma monetaria de los Reyes Católicos, así como las circunstancias políticas y económicas de Castilla durante la primera mitad del siglo XVI, hicieron que prácticamente no sufrieran alteración alguna hasta el año 1566. La única modificación reseñable en este periodo fue la efectuada por el Emperador Carlos $\mathrm{V}$ al crear una nueva moneda de oro, el escudo, enmarcado dentro del permanente conflicto con Francisco I de Francia, debido a que el monarca francés había creado una moneda nueva de oro, el escudo, de ley más baja que la del ducado castellano, lo que favorecía la fuga del oro castellano al ser de mejor calidad que el francés. Será en 1566, cuando la publicación de la ordenanza de 14 de noviembre, llamada Pragmática de la Nueva Estampa, creará una moneda de vellón que será un claro precedente de lo que iba a ocurrir en el siglo XVII, porque la estricta reducción de la oferta de moneda de vellón puesta en práctica por los Reyes Católicos sería definitivamente abandonada por Felipe II debido a las necesidades de financiación del ingente déficit público que acumulaba. Este monarca reorientaría la política monetaria hacia expansión monetaria a través de emisiones masivas de moneda de vellón. La bancarrota de 1596 no fue suficiente para sanear las deudas acumuladas y recurrió a un arbitrio que después se utilizaría constantemente: la emisión de moneda de vellón con un valor nominal muy superior al intrínseco, eso sí, poniendo un tope de emisión de 340.000 marcos anuales ${ }^{10}$. Para llevar a cabo estas emisiones de vellón, Felipe II utilizaría el llamado Ingenio de Segovia11 ${ }^{11}$ un conjunto de máquinas instaladas en la ceca de Segovia con una tecnología que haría más difícil la falsificación de la moneda a la vez que incrementaba la velocidad de fabricación, su calidad y sobre todo proporcionaba una notable reducción de los costes de emisión. Felipe II y sus sucesores de esta manera pudieron acometer las masivas emisiones de moneda de vellón, con unas notables ganancias para la Real Hacienda.

10 Real Cédula 31 de diciembre de 1596 dada en Madrid "por la cual se ordenaba acuñar moneda de vellón sin plata en el Ingenio de Segovia, sin que las labores sobrepasen la cantidad de cien mil ducados cada año"

11 G. Murray (2006): La historia del Real Ingenio de la Moneda de Segovia, y el proyecto para su rehabilitación. Madrid, Fundación Real Ingenio de la Moneda de Segovia. 
La política monetaria adoptada durante el reinado de Felipe III tiene un rasgo directorio muy marcado, y es la consolidación del recurso a alterar el valor de la moneda, efectuando masivas emisiones de vellón sin liga de plata, o resellando la moneda, con un único fin, obtener recursos vía ingresos fiscales para financiar la política imperial, circunstancia que alcanzará su máxima expansión en el reinado de Felipe IV. Consecuencia de ello y como lógica reacción del mercado a las alteraciones monetarias, comenzarían a aparecer dos fenómenos que iban a dislocar aún más el sistema monetario, y que traerían de cabeza a los gobernantes, en primer lugar una aceleración constante del aumento del nivel de precios, y en segundo lugar, la aparición de un fenómeno conocido como premio de la plata.

Los grandes periodos de acuñación de vellón en Castilla fueron entre 1602 y 1606, en la monarquía de Felipe III, debido a la necesidad de financiación de las ingentes deudas heredadas de Felipe II, y entre 1618 y 1626 para afrontar el final de la tregua con Holanda y los gastos del inicio de la guerra de los Treinta Años, ya en el reinado de Felipe IV. Debido a las necesidades financieras de la Corona, después de 1626 comenzaron las operaciones de resello de las piezas, que producen beneficios más modestos pero nada despreciables, siendo en 1603, 1636, 1641, 1651, 1654 y 1661 los resellos más significativos. A medida que la conflictividad internacional aumentaba, en paralelo también lo hacia la presión ejercida sobre la Real Hacienda para obtener recursos.

Con el cambio de reinado y el acceso al poder de Olivares comenzaron los proyectos para reformar la situación de caos monetario. Los gobernantes de Castilla sabían que para combatir el exceso de moneda de vellón había que reducir su valor intrínseco, pero la merma de ingresos que esto provocaba sobre la Hacienda Real hacía muy complicado tomar esta medida además, incumplía los contratos firmados con asentistas. Los intentos de frenar la lógica reacción del mercado por las manipulaciones monetarias no tuvieron efecto alguno. Incluso el recurso a la legislación punitiva, utilizando el recurso a la Inquisición ${ }^{12}$ para luchar contra el pre-

12 El último recurso de los gobernantes para luchar contra la falsificación de moneda fue considerarla una causa de fe, y por lo tanto el delito sería juzgado en un 
mio, la falsificación de moneda y la salida de metal precioso, resultaría un fracaso.

En 1628, ante la escalada del nivel de precios y del premio, se llevó a cabo una deflación, publicada por decreto del 7 de agosto ${ }^{13}$, reduciendo el valor de la moneda de vellón a la mitad. El efecto inmediato de la medida fue una bajada del nivel de precios y del premio de la plata, sin embargo, el premio comenzó una escalada desde comienzos de 1629, debido a la captura de la Flota de Galeones y la pérdida de las remesas de plata por la guerra con Holanda. A la escasez de plata se le unió el mantenimiento del contrabando y la falsificación de moneda, y una crisis de subsistencia que obligó a importar trigo para abastecer a la población, aumentando el déficit de la balanza comercial. Con la deflación de 1628 comenzaría una serie de ciclos de inflación-deflación entre 1636 y 1651. El conflicto con Francia por la hegemonía europea, enmarcado dentro de la Guerra de los Treinta Años, presionó aun más si cabe las necesidades financieras de la Corona. El recurso para ello fue, además de incrementar la presión fiscal estableciendo nuevos impuestos, el resello de la moneda de vellón. Pero esta medida fue más perniciosa que las emisiones de vellón. La desconfianza de los particulares para llevar las monedas a las cecas para su resello fue evidente, pero además se encontraba con el problema de la falsificación de moneda, que producía beneficios para los que se dedicaban a esta tarea.

Los años finales del reinado de Felipe IV en el aspecto político, hacendístico y monetario son un triste epílogo de la dinastía de los Austrias. La derrota militar en todos los frentes europeos, una hacienda en completa bancarrota con una deuda estimada en 21.616.037 ducados ${ }^{14}$, y una inflación tan elevada que convertía la actividad comercial en algo extraordinario. En medio de este pano-

tribunal de la Santa Inquisición. La Inquisición tenía un carácter policiaco y judicial, contaba con gran cantidad de funcionarios y tribunales y sus sentencias tenían la ventaja de no admitir apelación. A pesar de todo, el efecto de esta medida fue casi nulo, porque la política represiva iba en contra de las leyes del mercado.

13 AHN Nobleza Osuna Leg. 2269, num. 11. También en Nueva Recopilación, Declaraciones, Libro V, Título XXI, Ley XXIII.

${ }^{14}$ Domínguez Ortiz, A. (1983): Política y Hacienda en el reinado de Felipe IV, pág. 80, Madrid, Ed. Pegaso. 
rama tan desolador comenzaría el reinado de Carlos II, un reinado que abordaría la definitiva estabilización y reforma del sistema monetario.

\section{El premio de la plata: alteraciones monetarias, crisis e inflación}

Las consecuencias de las constantes alteraciones monetarias fueron nefastas para la economía castellana. La abundancia de moneda de vellón aumentaba los precios al ser un numerario con un valor como metal inferior al valor nominal o facial, lo que repercutía negativamente en su aceptación en el comercio o en el crédito. Los vendedores trataban de compensar la reducción de la cantidad de metal contra el que se valoraba con un aumento del precio de los bienes, pero además se generaba un incremento de la velocidad de circulación del dinero de vellón, porque los tenedores de moneda buscaban deshacerse de ella lo más rápidamente posible, acelerando aún más la subida de los precios. Consecuencia de todo esto es la aparición del premio de la plata, que no es más que la división del sistema monetario ocasionado por la desvalorización de la moneda de vellón.

El premio de la plata era el sobreprecio de las piezas de plata respecto a las monedas de vellón, y se convirtió en un termómetro que medía la salud del sistema monetario, pues era esta la única manera a través de la cual los castellanos dieron a cada moneda no sólo su valor sino también el que le correspondía con relación a las otras. A medida que las alteraciones monetarias fueron mayores, el premio no dejaba de aumentar. Esta cantidad adicional de moneda de vellón que había que entregar para obtener una moneda de plata provocó en el mercado la aparición de dos precios diferentes para valorar las mercancías, según fuera el pago realizado en moneda de plata o de vellón. En definitiva era una prima de riesgo que establecía el mercado según la moneda que se utilizaba en las transacciones y su valor por los agentes.

El premio también se vio afectado por los defectos del sistema monetario, especialmente su rigidez para adaptarse a los cambios de equivalencias determinadas por el mercado. Además la 
constante salida de plata al exterior agravó la ya de por sí escasez de moneda de plata frente a la abundancia de vellón, aumentando el premio por la mayor estimación de la moneda de plata ${ }^{15}$.

PREMIO DE LA PLATA

\begin{tabular}{|c|c|c|c|c|c|}
\hline Año & Premio & Año & Premio & Año & Premio \\
\hline 1620 & 104,29 & 1640 & 144,68 & 1660 & 157,81 \\
\hline 1621 & 104,04 & 1641 & 165,75 & 1661 & 165,62 \\
\hline 1622 & 105,64 & 1642 & 224,45 & 1662 & 180,99 \\
\hline 1623 & 110,4 & 1643 & 128,3 & 1663 & 196,87 \\
\hline 1624 & 112,31 & 1644 & 130,09 & 1664 & 207,83 \\
\hline 1625 & 120,44 & 1645 & 132,74 & 1665 & 200,2 \\
\hline 1626 & 148,24 & 1646 & 138,76 & 1666 & 229,67 \\
\hline 1627 & 143,39 & 1647 & 138,08 & 1667 & 242,7 \\
\hline 1628 & 136,29 & 1648 & 141,38 & 1668 & 253,12 \\
\hline 1629 & 116,7 & 1649 & 145,18 & 1669 & 272,91 \\
\hline 1630 & 120,68 & 1650 & 150,69 & 1670 & 275 \\
\hline 1631 & 118,67 & 1651 & 153 & 1671 & 284,89 \\
\hline 1632 & 118,5 & 1652 & 150,25 & 1672 & 287,5 \\
\hline 1633 & 123,2 & 1653 & 150 & 1673 & 287,5 \\
\hline 1634 & 126,3 & 1654 & 150,5 & 1674 & 289,45 \\
\hline 1635 & 126,74 & 1655 & 150 & 1675 & 300,52 \\
\hline 1636 & 126,12 & 1656 & 150 & 1676 & 308,85 \\
\hline 1637 & 129,13 & 1657 & 156,25 & 1677 & 312,5 \\
\hline 1638 & 134,34 & 1658 & 164,58 & 1678 & 318,75 \\
\hline 1639 & 135,2 & 1659 & 161,98 & 1679 & 331,25 \\
\hline
\end{tabular}

15 Cálculos propios basados en la E.J. Hamilton, Tabla 7, p. 108 promedio de los índices del premio en Andalucía, Castilla La Nueva y Castilla La Vieja. E.J. Hamilton (1988): Guerra y precios 1650-1800, Madrid, Alianza Editorial. 
La subida de los precios y del premio se vio además agravada por los efectos de la introducción de moneda falsa, en el caso de la moneda de cobre, o de moneda con menor peso, para el caso de la moneda de plata. Los extranjeros, especialmente los franceses y los portugueses, introducían monedas de plata con un peso reducido, con el fin de sacar las monedas de plata castellanas legales, de mayor peso y calidad, contribuyendo así al aumento de la escasez de plata. Pero además, la moneda de vellón fue masivamente falsificada, introducida por extranjeros, pero especialmente falsificada en monasterios, provocando un crecimiento de la masa monetaria, haciendo más insostenible la subida de precios y del premio.

Las alteraciones monetarias, al expandir la cantidad de dinero y elevar los precios, provocaron una significativa alteración en el sistema económico y comercial, donde el premio de la plata no era mas que el reflejo de esa alteración. El premio y la consiguiente inflación tuvieron un impacto diferente en el entorno rural y en el mundo urbano. Las relaciones entre el ciudadano y la moneda se instauraron sobre unas bases lógicas y psicológicas diferentes, y esto se comprueba al analizar los resultados de las políticas monetarias aplicadas sobre estos dos entornos. Cuando el rey aumentaba el valor nominal de la moneda, creía tener el apoyo de los grupos campesinos quienes, endeudados crónicamente, no pueden sino esperar una desvalorización (en términos del intrínseco) para reducir sus cargas. Por el contrario, cuando el soberano revaluaba la moneda o disminuía su nominal, necesitaba obtener el consenso de los perceptores de rentas en general, propietarios de tierras, algunas categorías de artesanos y mercaderes, burócratas, arrendadores de bienes públicos, etc.

Ya fuera en el campo o en la ciudad, las clases endeudadas acogían de modo favorable el debilitamiento de la moneda, pero su fortaleza daba lugar a distintas reacciones. La de los campesinos era casi inexistente, mientras que en los estratos más bajos de la población urbana, era violenta y airada. En la ciudad se advertía más deprisa y con mayor dramatismo los efectos de los procesos deflacionarios. Los trabajadores de los gremios gozaban de mayores privilegios ante las variaciones de precios pero el resto de los asalariados prolongaban sus deudas continuamente esperando que se produjese una depreciación monetaria. Cuando en Castilla 
tenía lugar un resello de las monedas de vellón, se producía una avalancha de pagos de deudas, ya que las monedas pasaban a tener el doble o el triple de su valor.

En el caso de la nobleza, el clero y las oligarquías urbanas, la situación era diferente. En Castilla, a pesar de las quejas de las oligarquías de las ciudades frente a las masivas acuñaciones de vellón que tanto repercutían en la estabilidad de la moneda, y por ende de las rentas, la riqueza permaneció en sus manos gracias a la política antidevaluacionista de la moneda de plata desarrollada durante los siglos XVI y XVII por los Austrias. Política dirigida a mantener la reputación exterior, si, pero también estaba condicionada por el mantenimiento del status quo de las oligarquías. Los dueños de los metales preciosos, los sectores medios y altos de la sociedad, los tenían encerrados en casa o en manos de banqueros y hombres de negocios, que los hacían fructificar de manera oportuna. La posesión de una cierta cantidad de plata, y no digamos de oro, constituía una inversión cierta y rentable.

La Hacienda Real también sufrió las consecuencias de las alteraciones monetarias, ya que las consignaciones y los pagos que ésta efectuaba a los asentistas, juristas y a la burocracia estatal se efectuaban en moneda de plata, sin embargo, el pago de los impuestos se realizaba mayoritariamente en moneda de vellón. A la Monarquía española no le quedaba otra elección que aceptar los pagos en esta moneda porque con ello estaba respaldando la moneda que emitía, a pesar de todas las modificaciones que había sufrido. Conforme la moneda de vellón se acuñaba con mayor profusión, los arrendadores de impuestos y los tesoreros van a poner cada vez más exigencias para poder abonar en plata la recaudación, perjudicando gravemente a los juristas y librancistas, que eran en definitiva ahorradores, que recibían sus ingresos en moneda de vellón. Al considerable retraso en el pago de los juros y libranzas se unía la moneda, lo que en definitiva suponía un notable agravio para los ahorradores, mermando las posibilidades de inversión, y por tanto de crecimiento económico.

Finalmente otro de los problemas que ejercieron las alteraciones monetarias se fijaría con especial intensidad en el mercado del crédito. Cuando se realizaba un contrato de asiento o de préstamo, en los documentos siempre aparecía una cláusula específica que 
aseguraba la restitución del dinero en una determinada cantidad de piezas de oro y plata. Los préstamos establecidos en plata se podían restituir en vellón siempre y cuando se le añadiese una cantidad suplementaria de moneda fraccionaria o viceversa, un préstamo establecido en vellón se podía devolver en moneda de plata descontando el porcentaje del premio de la plata vigente en ese momento. En realidad se estaba favoreciendo a los deudores frente a los acreedores, pero las políticas inflacionistas lo que buscan, entre sus objetivos, es precisamente esto, minusvalorar las deudas contraídas.

En resumen, las alteraciones en su valoración global suponen la destrucción del sistema monetario, y con ello toda posibilidad de efectuar un cálculo económico viable por los agentes. Además, los agentes en su interrelación dentro del mercado tienen que afrontar una subida de precios consecuencia de las diferentes valoraciones que efectúan los individuos ante el nuevo valor de la moneda. Todo ello se traduce en inflación, lo que distorsiona más la actividad económica y comercial.

\section{Conclusiones}

Friederich von Hayek supo adivinar con extraordinario acierto que siempre que había un ejercicio sistemático de la coacción por parte del Estado, o se producía la concesión de privilegios y ventajas para determinados grupos o personas, se estaba violentando alguno de los principios universales del derecho, lo que terminaba por favorecer la aparición de graves y negativas consecuencias que afectaban al proceso de cooperación social. En nuestro caso, las alteraciones monetarias practicadas por la Monarquía Hispánica desde finales del siglo XVI, con especial intensidad en la primera mitad del siglo XVII, suponen un paso más en el intervencionismo sobre el mercado, la libertad económica individual y la propiedad privada, un intervencionismo que profundizó y alargó en el tiempo los efectos de la Decadencia Española del siglo XVII.

El intervencionismo del gobierno sobre el dinero tuvo consecuencias desastrosas para la economía. Por un lado el mercado reaccionó con una constante elevación del nivel de precios, pero 
además, ante las alteraciones efectuadas tanto en la ley como en el valor facial de las monedas de vellón, la ley de Gresham actuó, y tanto el oro como la plata se atesoraron y desaparecieron de la circulación, afectando al circuito comercial, que perdió sus medios de intercambio. Además el proceso inflacionario alteró de tal manera los precios, que los individuos perdieron el mecanismo principal por el cual podían efectuar el ejercicio del cálculo económico. A medida que el gobierno trató de impedir por medio de la coacción legislativa la reacción contraria a sus intereses de los individuos, el mercado reaccionó con la aparición del premio de la plata. El premio era en realidad un sobreprecio que se tenía que pagar por utilizar moneda de plata en lugar de vellón, y se convirtió en un termómetro que medía la salud del sistema monetario, o lo que es lo mismo, una prima de riesgo.

Los diferentes gobiernos que se enfrentaron a los problemas derivados de las alteraciones monetarias reaccionaron con medidas punitivas por un lado, pero también tomaron medidas deflacionarias para reducir el valor facial de la moneda de vellón, en un intento de frenar el premio y la subida de precios. Sin embargo, estas medidas no tuvieron continuidad; por el contrario, una sucesiva serie de medidas inflacionarias y deflacionarias acabaron con cualquier posible mecanismo de fijación de precios, y por lo tanto, de posibilidad de cálculo económico. Habría que esperar a finales del siglo XVII cuando la decidida actuación de los gobiernos del duque de Medinaceli y del conde de Oropesa estabilizarán el sistema monetario.

\section{BIBLIOGRAFIA}

Álvarez Nogal, C. (2000): El dilema monetario de la monarquía española en el siglo XVII. ¿Pequeñas monedas de plata o crédito internacional? Madrid, Dpto. Historia Económica Universidad Carlos III.

- (2000): El transporte de moneda en la España del siglo XVII: mecanismos y costes. Madrid, Dpto. Historia Económica Universidad Carlos III. 
- (2000): La moneda de vellón y su influencia en la negociación del crédito en la monarquía durante el siglo XVII, Madrid, Dpto. Historia Económica Universidad Carlos III.

Biblioteca Digital de Castilla y León: Nueva Recopilación de las Leyes de Castilla (1569), www.bibliotecadigital.jcyl.es

Cánovas del Castillo, A. (1910): Historia de la Decadencia de España desde Felipe III hasta Carlos II, J. Ruiz Editor, Madrid.

Cipolla, C. (1994): El gobierno de la moneda. Ensayos de historia monetaria, Barcelona, Editorial Crítica.

- (1985): La decadencia económica de los imperios, Madrid, Alianza Editorial.

de Santiago, J. (2000): Política monetaria en Castilla durante el siglo XVII, Valladolid, Junta de Castilla y León.

Deleito y Piñuela, J. (1969): El declinar de la monarquía española, Madrid, Editorial Espasa Calpe.

Domínguez Ortiz, A. (1969): Las remesas de metales preciosos de Indias en 1621-1665, Anuario de Historia Económica y Social II.

- (1984): Política fiscal y cambio social en la España del siglo XVII, Instituto de Estudios Fiscales.

- (1983): Política y hacienda de Felipe IV, Madrid, Ediciones Pegaso

Eagleton, C y Williams, J: (2009): Historia del dinero, Madrid, Editorial Paidos.

Font de Villanueva, C. (2005): "Política monetaria y política fiscal en Castilla en el siglo XVII: un siglo de inestabilidades", Revista de Historia Económica n ${ }^{\circ}$ 23, págs. 329-348.

García Guerra, E. (2000): Las alteraciones monetarias en Europa durante la Edad Moderna, Madrid, Editorial Arco Libros.

- (2003) Moneda y arbitrios. Consideraciones del siglo XVII, Madrid, CSIC.

Hamilton, E.J. (2000): El tesoro americano y la revolución de los precios 1501-1640, Barcelona, Editorial Crítica.

- (1988): Guerra y precios 1650-1800, Madrid, Alianza Editorial.

Huerta de Soto, J. (1992): Socialismo, cálculo económico y función empresarial, Madrid, Unión Editorial ( $6^{a}$ edición, 2020).

- (2012) La Escuela Austriaca: mercado y creatividad empresarial, editorial Síntesis.

Mises, L von. (2004): La acción humana, Madrid, Unión Editorial.

- (2012): La teoría del dinero y del crédito, Madrid, Unión Editorial. 
Murray, G. (2006): La historia del Real Ingenio de la Moneda de Segovia. Fundación Real Ingenio de la Moneda de Segovia.

Palacio Atard, V. (1949): Derrota, agotamiento y decadencia en la España del siglo XVII, Madrid, Editorial Rialp.

Pieper, R. (1987): La Revolución de los precios en España: sus causas y sus efectos, Barcelona, Ed. Ancora.

Rothbard, Murray N. (2009): Qué le hizo el gobierno a nuestro dinero. Ensayo sobre el origen y función de la moneda, Madrid, Unión Editorial.

- (2013): El hombre, la economía y el Estado, Madrid, Unión Editorial. Trevor Davies, R. (1972): La Decadencia española 1621-1700, Madrid, Editorial Labor. 